УДК 547.972

\title{
ФЛАВОНОИДЫ НАДЗЕМНОЙ ЧАСТИ АLНАGI CANESCENS ФЛОРЫ УЗБЕКИСТАНА
}

\author{
() С.3. Нишанбаев ${ }^{I *}$, Х.М. Бобакулов ${ }^{1}$, Н.Ю. Бешко ${ }^{2}$, И.Д. Шамьянов ${ }^{1}$, Н.Д. Абдуллаев ${ }^{1}$ \\ ${ }^{1}$ Институт химии растительных веществ им. акад. С.Ю. Юнусова АН РУ,, \\ ул. Мирзо Улугбека, 77, Ташкент, 100170 (Республика Узбекистан), \\ e-mail: sabir78@rambler.ru \\ ${ }^{2}$ Институт генофоноа растительного и животного мира АН РУз, \\ ул. Богишамол, 232, Ташкент, 100125 (Республика Узбекистан)
}

Целью данной работы является фитохимическое исследование ранее не изученного вида янтака - Alhagi canescens (янтак седоватый, верблюжья колючка седоватая). Вид распространен на территории Узбекистана, Таджикистана, Туркменистана, Афганистана и в Южном Казахстане, в Кызылкуме, Каракумах, долинах рек Сырдарьи и Амударьи, Сырдарьинском Каратау, Юго-Западном Тянь-Шане и Южном Памиро-Алтае.

Исследованы фенольные соединения надземной части (стебли, листья, колючки и цветки) Alhagi canescens (Regel) B. Keller \& Shap. - (янтак седоватый или верблюжья колючка седоватая, семейство Fabaceae), произрастающего в Узбекистане. Впервые из данного вида янтака методом колоночной хроматографии из этилацетатной фракции водноэтанольного экстракта последовательно выделены следующие биологически активные флавоноиды: кемпферол $(0,054$ г, $0,22 \%$ в пересчете на сухую массу этилацетатного извлечения), кверцетин $(0,065$ г, 0,26\%), изорамнетин $(0,072$ г; $0,29 \%)$, хризоспленетин $(0,082$ г; 0,33\%), (+)-катехин $(0,022$ г; 0,09\%), (-)-эпигаллокатехингаллат $(0,026$ г; 0,10\%), изокверцитрин $(0,087 \Gamma ; 0,35 \%)$, изорамнетин-3-O- $\beta$ - $D$-глюкопиранозид $(0,175 \Gamma ; 0,7 \%)$, нарциссин $(0,212$ г; $0,85 \%)$, и рутин $(0,108$ г; 0,43\%). Выделенные флавоноиды идентифицированы спектральными методами (ИК-, УФ- и ЯМРспектров) и сравнением их с достоверно известными образцами.

Ключевые слова: Alhagi canescens (Regel) B. Keller \& Shap., Fabaceae, флавонолы, флавоны и флаван-3-олы.

Работа выполнена при финансовой поддержке программы фундаментальных научных исследований АН РУз (грант ФА-Ф7-T184 и ФA-Ф7-T185).

\section{Введение}

Согласно различным источникам в мировой флоре род Alhagi Tournex Adans. (верблюжья колючка, янтак) представлен 7 видами, центром видового разнообразия является восточная часть Древнего Среди-

Нишанбаев Сабир Зарипбаевич - старший научный сотрудник лаборатории химии кумаринов и терпеноидов, e-mail: sabir78@rambler.ru Бобакулов Хайрулла Мамадиевич - кандидат химических наук, старший научный сотрудник лаборатории физических методов исследований, e-mail: sabir78@rambler.ru

Бешко Наталья Юрьевна - кандидат биологических наук, старший научный сотрудник лаборатории Центральный гербарий, e-mail: natalia_beshko@mail.ru Шамьянов Ильдар Джамилович - старший научный сотрудник лаборатории химии кумаринов и терпеноидов, e-mail: sabir78@rambler.ru Абдуллаев Насрулла Джалилович - кандидат химических наук, ведущий научный сотрудник лаборатории физических методов исследований, e-mail: sabir78@rambler.ru земноморья [1-4]. В Средней Азии (включая Узбекистан) произрастает 5 видов: Alhagi pseudalhagi (M.Bieb.) Desv.ex Shap. - янтак ложный (верблюжья колючка ложная), Alhagi sparsifolia Shap. - янтак редколистный (верблюжья колючка редколистная), Alhagi canescens (Regel) B. Keller \& Shap. - янтак седоватый (верблюжья колючка седоватая), Alhagi kirghisorum Schrenk. - янтак киргизский (верблюжья колючка киргизская), Alhagi persarum Boiss. \& Buhse. - янтак персидский (верблюжья колючка персидская) [1, 4-5].

Фармакологические исследования показали, что экстракты и индивидуальные фенольные соединения растений рода Alhagi обладают противови-

\footnotetext{
* Автор, с которым следует вести переписку.
} 
русным, антибактериальным, антиоксидантным, гепатопротекторным, диуретическим, противоопухолевым, противовоспалительным и противовирусным свойствами [6-8].

К настоящему времени из пяти видов растений рода Alhagi, произрастающих в Узбекистане, в химическом отношении исследованы два: Alhagi pseudalhagi и Alhagi sparsifolia, показано, что эти виды продуцируют в мажорных количествах биологически активные флавоноиды, проантоцианидины, терпеноиды (включая стероиды) и жирные кислоты [9-14]. А из популяции Alhagi pseudalhagi и Alhagi sparsifolia, произрастающих в Индии и Китае, выделены ряд минорных алкалоидов [15-16].

В связи с этим химическое исследование растений данного рода с целью поиска новых биологически активных природных соединения весьма актуально.

Целью данной работы является фитохимическое исследование ранее не изученного вида янтака Alhagi canescens (янтак седоватый, верблюжья колючка седоватая). Вид распространен на территории Узбекистана, Таджикистана, Туркменистана, Афганистана и в Южном Казахстане, в Кызылкуме, Каракумах, долинах рек Сырдарьи и Амударьи, Сырдарьинском Каратау, Юго-Западном Тянь-Шане и Южном Памиро-Алае.

В пределах Узбекистана этот вид произрастает в песчаных пустынях, предгорных полынносолянковых полупустынях, тугаях, вдоль рек, каналов и арыков, в посевах, на залежах и пустырях. В отличие от практически повсеместно распространенных Alhagi pseudalhagi и Alhagi kirghisorum, на территории страны это вид верблюжьей колючки встречается спорадически, главным образом в освоенных районах Ферганской, Сырдарьинской, Джизакской, Бухарской, Кашкадарьинской и Сурхандарьинской областей Узбекистана $[6,17]$.

\section{Экспериментальная часть}

Растительное сырье. Для проведения исследования надземная часть Alhagi canescens была собрана в период цветения (июль 2014 г.) в окрестностях села Тогай Узбекистанского района Ферганской области Республики Узбекистан. Видовую принадлежность определили при помощи «Определителя растений Средней Азии» [5] и сопоставления собранных гербарных материалов с образцами Alhagi canescens, хранящимися в Центральном гербарии Узбекистана (TASH). Следует отметить, что от остальных представителей рода Alhagi данный вид хорошо отличается опушенными листьями, верхушками стеблей, цветоножками и чашечками.

Экстракиия и выделение флавоноидов надземной части Alhagi canescens. Высушенную и измельченную надземную часть (2,0 кг) экстрагировали при комнатной температуре 7 раз $70 \%$ водным этанолом. Объединенный водно-спиртовой экстракт сгущали в вакууме до 1 л и разбавляли водой до 2 л, последовательно встряхивали с хлороформом, этилацетатом и $н$-бутанолом. Отогнав растворители, получили 10,5 г хлороформной, 34,4 г этилацетатной и 155 г н-бутанольной фракции.

Хроматографическим разделением этилацетатной фракции (25 г) водно-спиртового экстракта надземной части янтака седоватого на силикагеле (880 г, силикагель 150/200 mesh), при элюировании колонки хлороформом, системой хлороформ - метанол в различных соотношениях $(1: 0,9: 1,1: 5)$ с последующим рехроматографированием отдельных элюатов на сефадексе LH-20, элюируя смесью метанол - вода с нарастающим градиентом концентрации воды $\left(\mathrm{MeOH}-\mathrm{H}_{2} \mathrm{O}\right)$. Из полученных элюатов последовательно выделили кемпферол (1) $(0,054$ г, 0,22\% в пересчете на сухую массу этилацетатного извлечения), кверцетин (2) $(0,065$ г, 0,26\%), 0,072 г изорамнетин (3) $(0,072$ г; 0,29\%), хризоспленетин (4) $(0,082$ г; 0,33\%), (+)катехин (5) (0,022 г; 0,09\%), (-)-эпигаллокатехингаллат (6) $(0,026$ г; 0,10\%), изокверцитрин (7) $(0,087$ г; $0,35 \%)$, изорамнетин-3-O- $\beta$ - $D$-глюкопиранозид (8) $(0,175$ г; $0,7 \%)$, нарциссин $(9)(0,212 \Gamma ; 0,85 \%)$ и рутин (10) $(0,108$ г; $0,43 \%)$.

Общие экспериментальные условия. Для колоночной хроматографии (КХ) использовали силикагель 150/200 меш, КСК фирмы «Tianjin Sinomed Pharmaceutical» (China), Sephadex LH-20 сорбент фирмы «GE Healthcare Bio-Sciences AB» (Sweden); для тонкослойной хроматографии (TCX) - пластины «Silufol UV254». Для ТСХ флавоноидов использовали системы растворителей: $\mu$-бутанол - уксусная кислота - вода (4:1:5), хлороформ - метанол - уксусная кислота - вода $(9: 3: 0,5: 0,5)$. На хроматограммах фенольные соединения обнаруживали по характерному свечению в УФ-свете при длине волны 254 нм до 365 нм и после обработки хроматограмм парами аммиака, $1 \%$ спиртовым раствором алюминия хлорида, $1 \%$ рас- 
твор ванилина в $5 \%$ спиртовом растворе серной кислоты. ${ }^{1} \mathrm{H},{ }^{13} \mathrm{C}$ ЯМР спектры снимали на приборе Unity 400 plus (Varian, США, 400 МГц для ${ }^{1} \mathrm{H}$ и 100 МГц для ${ }^{13} \mathrm{C}$ ) в растворах Рy- $d_{5}$, DMSO- $d_{6}$ и $\mathrm{CD}_{3} \mathrm{OD}$. В качестве внутреннего стандарта в спектрах ${ }^{1} \mathrm{H}$ ЯМР использовали ГМДС (0 м.д.). Инфракрасные спектры выделенных веществ снимали на приборе System 2000 FT IR (Perkin Elmer, США) в виде таблеток с КBr. УФ-спектры сняты в спиртовом растворе на приборе Lambda-16 (Perkin Elmer, США).

\section{Обсуждение результатов}

Нами проведены качественные реакции на наличие алкалоидов в извлечениях из травы Alhagi canescens. В экстрактах этого вида верблюжьей колючки алкалоиды не обнаружены.

В результате проведенных исследований из этилацетатной фракции водно-этанольного экстракта выделили десять соединения флавоноидного характера.

Выделенные флавоноиды идентифицировали сравнением спектральных характеристик веществ (УФ-, ИК-, ЯМР ${ }^{1} \mathrm{H},{ }^{13} \mathrm{C}-$ спектры) с описанными в литературе, а также непосредственным сравнением с достоверными образцами флавоноидов, выделенных нами из других видов растений.

На основании изучения спектральных данных флавоноиды 1-3 и 7-10 отнесены к производным флавонола, соединения 5 и 6 - флаван-3-ола, а соединения 4 к производным флавона. Ниже проводим данные по идентификации выделенных флавоноидов.

Кемпферол (3,5,7,4'-тетрагидроксифлавонол) (1). Желтый аморфный порошок, состава $\mathrm{C}_{15} \mathrm{H}_{10} \mathrm{O}_{6}$, с т.пл. $265-266{ }^{\circ} \mathrm{C}, \mathrm{R}_{f} 0,23$ (хлороформ - метанол-уксусная кислота - вода $9: 3: 0,5: 0,5$ ). УФ-спектр $\left(\mathrm{C}_{2} \mathrm{H}_{5} \mathrm{OH}, \lambda_{\max }\right.$ нм): 256, 357. ИК-спектр $\left(\mathrm{KBr}, v, \mathrm{~cm}^{-1}\right): 3430-3320$ (ОН группа), 1650 (C=O, $\gamma$-пирон), 1590, 1540 (колебания ароматического ядра).

Флавоноид 1 идентифицировали на основании сравнения результатов со стандартным образцом [18].

Кверцетин (3,5,7,3',4'-пентагидроксифлавонол) (2). Желтый аморфный порошок состава $\mathrm{C}_{15} \mathrm{H}_{10} \mathrm{O}_{7}$, ст.пл. $298-301{ }^{\circ} \mathrm{C}$. УФ-спектр $\left(\mathrm{C}_{2} \mathrm{H}_{5} \mathrm{OH}, \lambda_{\max }\right.$ нм): 256, 374. ИК-спектр $\left(\mathrm{KBr}, v, \mathrm{~cm}^{-1}\right): 3402-3120(\mathrm{OH}), 1664$ (C=O, $\gamma$-пирон), 1610-1522 (ароматические $\mathrm{C}=\mathrm{C}$ связи), 1449, 1382, 1318, 1262, 1168, 1014.

${ }^{1} \mathrm{H}$ ЯМР-спектр: (400 МГц, Ру- $d_{5}, \delta$, м.д., J/Гц): 6,74 (1Н, уш.с. Н-6), 6.77 (1Н, с, Н-8), 7,63 (1Н, д, J=1,9, Н-2'), 7,40 (1H, д, $\left.J=8,5, \mathrm{H}-5^{\prime}\right), 8,13$ (1H, дд, $J=8,5 ; 1,9, \mathrm{H}-6$ '), 13,35 (1H, с, 5-OH), 11,93 (3Н, уш.с., ОН).

${ }^{13}$ С ЯМР-спектр: (100МГц, Ру- $d_{5}, \delta$, м.д.): 177,74 (С-4), 165,96 (С-7), 162,89 (С-5), 157,90 (С-9), 148, 17 (C-2), 147,55 (C-3'), 138,36 (C-3), 124,29 (C-1'), 121,49 (C-6'), 117,10 (C-2', C-5'), 104,90 (C-10), 99,66 (C-6), 94,74 (C-8) [18].

Изорамнетин (3,5,7,4'-тетрагидрокси-3'-метоксифлавонол) (3). Желтый аморфный порошок состава $\mathrm{C}_{16} \mathrm{H}_{12} \mathrm{O}_{7}$, с т.пл. 302-304 ${ }^{\circ} \mathrm{C}, \mathrm{R}_{f}$ 0,32 (хлороформ - метанол - уксусная кислота - вода $\left.9: 3: 0,5: 0,5\right)$. УФспектр $\left(\mathrm{C}_{2} \mathrm{H}_{5} \mathrm{OH}, \lambda_{\max }\right.$ нм): 253, 370. ИК-спектр $\left(\mathrm{KBr}, v, \mathrm{~cm}^{-1}\right): 3420(\mathrm{OH}), 2890\left(\mathrm{OCH}_{3}\right), 1646(>\mathrm{C}=\mathrm{O}), 1605$, 1568, 1505 (ароматические $\mathrm{C}=\mathrm{C}$-связи), 842, 817 ( $n$-замещение в кольце «В»).

Флавонол 3 идентифицирован на основании физико-химических констант, температуры плавления и сравнения со стандартным образцом [19].

Хризоспленетин (5,4'-дигидрокси-3,6,7,3'-тетраметоксифлавон) (4). Желтый аморфный порошок состава $\mathrm{C}_{19} \mathrm{H}_{18} \mathrm{O}_{8}$, с т.пл. $187-188^{\circ} \mathrm{C}$. УФ-спектр $\left(\mathrm{C}_{2} \mathrm{H}_{5} \mathrm{OH}, \lambda_{\max }\right.$ нм): $258,271,353$. ИК-спектр $\left(\mathrm{KBr}, v, \mathrm{~cm}^{-1}\right)$ : $3349(\mathrm{OH}), 2940,2835\left(\mathrm{OCH}_{3}\right), 1658(\mathrm{C}=\mathrm{O}, \gamma$-пирон), 1603-1514 (ароматические $\mathrm{C}=\mathrm{C}$-связи), 1489, 1459 , 1430, 1357, 1289, 1273, 1248, 1205, 1166, 1132, 1098, 1066, 1030.

${ }^{1} \mathrm{H}$ ЯМР-спектр: (400 МГц, DMSO- $d_{6}, \delta$, м.д., Ј/Гц): 6,91 (1Н, уш. с, Н-8), 6,97 (1Н, д, $J=8,4$ H-5 ), 7,64 (1H, дд, $\left.J=8,4 ; 2,1, \mathrm{H}^{-} 6^{`}\right), 7,68\left(1 \mathrm{H}\right.$, д, $\left.J=2,1, \mathrm{H}-2^{\prime}\right) 9,95$ (1Н, уш. с, 4`-OH), $12,64(1 \mathrm{H}$, с, 5-OH), 3,74 $\left(3 \mathrm{H}, \mathrm{c}, 7-\mathrm{OCH}_{3}\right), 3,82\left(3 \mathrm{H}, \mathrm{c}, 3^{\prime}-\mathrm{OCH}_{3}\right), 3,88\left(3 \mathrm{H}, \mathrm{c}, 6-\mathrm{OCH}_{3}\right), 3,92\left(3 \mathrm{H}, \mathrm{c}, 3-\mathrm{OCH}_{3}\right)$.

${ }^{13} \mathrm{C}$ ЯМР-спектр: (100 МГц, DMSO-d 6 , $\delta$, м.д.): 178,19 (С-4), 158,62 (С-7), 155,74 (C-2), 151,71 (С-9), 151,64 (C-5), 149,90 (C-4'), 147,48 (C-3'), 137,72 (C-3), 131,58 (C-6), 122,31 (C-6'), 120,71 (C-1'), 115,63 (C-5'), $112,05\left(\mathrm{C}-2^{\prime}\right), 105,55(\mathrm{C}-10), 91,41(\mathrm{C}-8), 60,03\left(7-\mathrm{OCH}_{3}\right), 59,67\left(3{ }^{\prime}-\mathrm{OCH}_{3}\right), 56,47\left(3-\mathrm{OCH}_{3}\right), 55,78\left(6-\mathrm{OCH}_{3}\right)$.

Хризоспленетин (4) идентифицирован на основании полученных спектральных данных и их сравнения с описанными в литературе [19].

(+)-Катехин ((2R,3S)-2-(3,4-дигидроксифенил)-3,4-дигидро-2Н-хроман-3,5,7-триол) (5). Беловатый аморфный порошок состава $\mathrm{C}_{15} \mathrm{H}_{14} \mathrm{O}_{6}$, с т.пл. $177-178{ }^{\circ} \mathrm{C}, \mathrm{R}_{f} 0.29$ (система: хлороформ - метанол - 
уксусная кислота - вода $9: 3: 0,5: 0,5)$, отнесен к мономерным формам флаван-3-олов по их качественной реакции с ванилином (красное окрашивание), характерной для флаван-3-олов. УФ-спектр (EtOH, $\lambda_{\max } \mathrm{HM)}$ : 205, 280. ИК-спектр (KBr, $v$, cм$\left.^{-1}\right): 3369,2885,1630,1518,1457,1286,1230,1177,1069,885$.

${ }^{1} \mathrm{H}$ ЯМР-спектр: (400 МГц, $\mathrm{CD}_{3} \mathrm{OD}, \delta$, м.д., J/Гц): 2,44 (1Н, дд, $\left.J=16,1 ; 8,1, \mathrm{H}-4 a\right), 2,78$ (1Н, дд, $J=16,1$; 5,4, H-4e), 3,91 (1Н, дт, $J=8,0 ; 5,2, \mathrm{H}-3), 4,50(1 \mathrm{H}$, д, $J=7,5, \mathrm{H}-2), 5,79(1 \mathrm{H}$, д, $J=2,3, \mathrm{H}-6), 5,86(1 \mathrm{H}, ~ д, ~ J=2,3$, H-8), 6,77 (1Н, д, $\left.J=2,2, \mathrm{H}-2^{\prime}\right), 6,65$ (1Н, дд, $\left.J=8,1 ; 2,2, \mathrm{H}-6^{\prime}\right), 6,70$ (1H, д, $\left.J=8,1, \mathrm{H}-5^{\prime}\right)$.

${ }^{13} \mathrm{C}$ ЯМР-спектр: (100 МГц, $\mathrm{CD}_{3} \mathrm{OD}, \delta$, м.д.): 82,97 (C-2), 68,93 (C-3), 28,66 (C-4), 157,71 (C-5), 96,37 (C-6), 157,95 (C-7), 95,59 (C-8), 157,03 (C-9), 100,91 (C-10), 132,30 (C-1'), 115,35 (C-2'), 146,36 (C-3', 4'), $116,19\left(\mathrm{C}-5^{\prime}\right), 120,17\left(\mathrm{C}-6^{\prime}\right)$.

Сравнивая выше изложенные спектральные данные с литературными [20], вещество 5 идентифицировали как (+)-катехин.

(-)-Эпигаллокатехин-3-О-галлат (6). Беловатый аморфный порошок состава $\mathrm{C}_{22} \mathrm{H}_{18} \mathrm{O}_{11}$, с т.пл. 210-211 ${ }^{\circ} \mathrm{C}, \mathrm{R}_{f} 0,6$, (система: $н$-бутанол - уксусная кислота - вода $4: 1: 5$ ), отнесен к мономерным формам флаван-3-олов. Образование с солями железа комплексов синего цвета свидетельствует о наличии в них ароматического кольца с тремя вицинальными гидроксильными группами. УФ-спектр (EtOH, $\left.\lambda_{\max } \mathrm{Hм}\right): 250$. ИК-спектр (KBr, $v$, cм$\left.^{-1}\right)$ : 3350-3141, 1692, 1618, 1544, 1447, 1222, 1176, 1068, 1010, 885.

${ }^{1} \mathrm{H}$ ЯМР-спектр: (400 МГц, $\mathrm{CD}_{3} \mathrm{OD}, \delta$, м.д., Ј/Гц): 2,77 (1Н, дд, $\left.J=17,3 ; 2,7, \mathrm{H}-4 a\right), 2,92$ (1Н, дд, $J=17,3 ; 4,7$, H-4e), 4,87 (1H, м, H-2), 5,46 (1H, м, H-3), 5,89 (2H, c, H-6, H-8), 6,43 (2H, c,H-6', H-2'), 6,88 (2H, c,H-6", H-2"').

${ }^{13} \mathrm{C}$ ЯМР-спектр: (100 МГц, СD ОD, $\delta$, м.д.): 78,73 (С-2), 70,06 (C-3), 26,98 (C-4), 157,97 (C-5), 96,61 (C-6), 157,97 (C-7), 95,97 (C-8), 157,33 (C-9), 99,52 (C-10), 130,90 (C-1'), 106,97 (C-2', 6'), 146,79 (C-3',5'), 133,89 (C-4'), 121,59 (C-1"), 110,35 (C-2", 6"), 146,79 (C-3", 5"), 139,90 (C-4"), 167,7 (C-7").

В ${ }^{13} \mathrm{C}$ ЯМР-спектре вещества 6 присутствуют сигналы атомов углерода галловой кислоты: карбоксильный атом углерода резонирует при $\delta 167,76$ м.д., С-1" при $\delta 121,59$ м.Д., С-2" и С-6" при $\delta 110,35$ м.Д., C-3", C-5" - при $\delta 146,39$ м.д. Характеристичный для галловой кислоты сигнал атома углерода C-4' прописывается при $\delta 139,90$ м.д. Атомы углерода С-2, С-3 и С-4 дают резонансные сигналы при $\delta 78,73,70,06$ и 26,98 м.д.. Эти спектральные характеристики соответствуют описанным в литературе [21].

Изокверцитрин (кверцетин-3-O- $\beta$ - $D$-глюкозид) (7). Желтый порошок состава $\mathrm{C}_{21} \mathrm{H}_{20} \mathrm{O}_{12}$, с т. пл. $236-238{ }^{\circ} \mathrm{C}, \mathrm{R}_{f} 0,71$ (хлороформ - метанол - уксусная кислота - вода $\left.9: 3: 0,5: 0,5\right)$. УФ-спектр $\left(\mathrm{C}_{2} \mathrm{H}_{5} \mathrm{OH}\right.$, $\lambda_{\max }$ Нм): 259, 364 нм. ИК-спектр $\left(v_{\max }, \mathrm{cm}^{-1}\right): 3114,2980,2900,1715,1656,1606,1550,1505$.

Прямым сравнением полученных УФ- и ИК-спектров с таковыми стандартного образца [22], вещество 7 идентифицировали как 5,7,3',4'-тетрагидрокси-флавон-3-O- $\beta$ - $D$-глюкозид.

Изорамнетин-3-O- $\boldsymbol{\beta}$ - $\boldsymbol{D}$-глюкопиранозид (8). Желтый аморфный порошок состава $\mathrm{C}_{22} \mathrm{H}_{22} \mathrm{O}_{12}$, с т.пл. 168-170 ${ }^{\circ} \mathrm{C}$. УФ-спектр $\left(\mathrm{C}_{2} \mathrm{H}_{5} \mathrm{OH}, \lambda_{\max }\right.$ нм): 256, 267 пл., 357 нм. ИК-спектр $\left(\mathrm{KBr}, v\right.$, cм$\left.^{-1}\right): 3546-3382(\mathrm{OH})$, 2925 (свидетельствует о наличии метоксильной группы $\left.\mathrm{OCH}_{3}\right), 1649(>\mathrm{C}=\mathrm{O}$ карбонильная группа $\gamma$-пиронового кольца), 1603 (валентные колебания двойных связей бензольных колец), 1566-1497 (ароматические двойные связи), 1393, 1355, 1293, 1054.

${ }^{1} \mathrm{H}$ ЯМР-спектр:(400 МГц, DMSO- $d_{6}, \delta$, м.д., Ј/Гц): 3,80 (1H, с, $\left.\mathrm{OCH}_{3}\right), 5,54(1 \mathrm{H}$, д, $J=7,2, \mathrm{H}-1 "), 6,18$ $(1 \mathrm{H}$, д, $J=2.1, \mathrm{H}-6), 6,41(1 \mathrm{H}$, д, $J=2.1, \mathrm{H}-8), 6,88(1 \mathrm{H}$, д, $J=8.4, \mathrm{H}-5 '), 7,46$ (1H, дд, $\left.J=8,4 ; 2,1, \mathrm{H}-6^{\prime}\right), 7,91$ (1H, д, $\left.J=2,1, \mathrm{H}-2^{\prime}\right)$.

${ }^{13} \mathrm{C}$ ЯМР-спектр: (100 МГц, DMSO- $d_{6}, \delta$, м.д.): 177,54 (C-4), 164,27 (C-7), 161,34 (C-5), 156,52 (C-9), 156,45 (C-2), 149,50 (C-3'), 146,99 (C-4'), 133,07 (C-3), 122,17 (C-6'), 121,21 (C-1'), 115,34 (C-5'), 113,57 (C-2'), 104,17 (C-10), 100,88 (C-1"), 98,86 (C-6), 93,85 (C-8), 77,55 (C-3"), 76,51 (C-5"), 74,46 (C-2"), 69,92 (C-4"), 60,70 (C-6"), 55,80 ( $\left.\mathrm{OCH}_{3}\right)$.

Сравнение спектральных данных и с таковыми подлинного образца 8 идентифицировали с 3,5,7,4'тетраокси-3'-метоксифлавон-3-O- $\beta-D$-глюкопиранозид [23].

Нарциссин (изорамнетин-3-O- $\beta$ - $D$-глюкопиранозил-6- $O-L$-рамнопиранозид) (9). Желтый аморфный порошок состава $\mathrm{C}_{28} \mathrm{H}_{32} \mathrm{O}_{16}$, с т.пл. $180-182^{\circ} \mathrm{C}$. УФ-спектр $\left(\mathrm{C}_{2} \mathrm{H}_{5} \mathrm{OH}, \lambda_{\max }\right.$ нм): 256, 268 пл., 360. ИК-спектр $\left(\mathrm{KBr}, v, \mathrm{~cm}^{-1}\right): 3384(\mathrm{OH}), 2935$ (свидетельствует о наличии метоксильной группы $\left.\mathrm{OCH}_{3}\right), 1656(>\mathrm{C}=\mathrm{O}$ карбонильная группа $\gamma$-пиронового кольца), 1604 (валентные колебания двойных связей бензольных колец), 1508 (ароматические двойные связи), 1355, 1209, 1060. 
${ }^{1} \mathrm{H}$ ЯМР-спектр: (400 МГц, $\mathrm{CD}_{3} \mathrm{OD}, \delta$, м.д., J/Гц): 1,04 (1Н, д, J=6,1, Н-6"' ), 3,16-3,90 (6Н, м, глюкоза - Н-2", Н-3", Н-4", Н-5", Н-6"), 3,16-3,90 (3Н, м, рамноза - Н-3"', Н-4"', Н-5"'), 3,59 (1Н, дд, J=3,4; J=1,6, Н$\left.2^{\prime \prime \prime}\right), 3,86\left(3 \mathrm{H}\right.$, с, $\left.\mathrm{OCH}_{3}\right), 4,47$ (1H, д, $\left.J=1,6, \mathrm{H}-1^{\prime \prime}\right), 5,14$ (1Н, д, $\left.J=7,7, \mathrm{H}-1 "\right), 6,08$ (1H, д, $\left.J=2,1, \mathrm{H}-6\right), 6,24$ (1H, д, $J=2,1, \mathrm{H}-8), 6,81\left(1 \mathrm{H}\right.$, д, $\left.J=8,5, \mathrm{H}^{\prime} 5^{\prime}\right), 7,50$ (1Н, дд, $\left.J=8,5 ; 2,1, \mathrm{H}-6 '\right), 7,85$ (1H, д, $\left.J=2,1, \mathrm{H}^{\prime} 2^{\prime}\right)$.

${ }^{13} \mathrm{C}$ ЯМР-спектр: (100 МГц, $\mathrm{CD}_{3} \mathrm{OD}, \delta$, м.д.): 179,04 (C-4), 165,92 (C-7), 162,65 (C-5), 158,59 (C-9), 158,17 (C-2), 150,66 (C-3'), 148,05 (C-4'), 135,42 (C-3), 123,85 (C-6'), 122,75 (C-1'), 115,95 (C-5'), 114,44 (C-2'), 105,49 (C-10), 104,54 (рамноза - 1), 102,42 (глюкоза - 1), 99,95 (C-6), 94,96 (C-8), 78,01 (глюкоза - 3), 77,15 (глюкоза - 5), 75,84 (глюкоза - 2), 73,77 (рамноза - 4), 72,18 (рамноза - 3), 71,94 (рамноза - 2), 71,46 (глюкоза - 4), 69,69 (рамноза - 5), 68,45 (глюкоза - 6), 56,66 (3'-ОСН $), 17,84$ (рамноза - 6).

На основании полученных данных вещество 9 идентифицировали как изорамнетин-3-O- $\beta-D$ рутинозид [24].

Рутин (кверцетин-3-O- $\beta$ - $D$-рутинозид) (10). Зеленовато-желтый мелкокристаллический порошок состава $\mathrm{C}_{21} \mathrm{H}_{30} \mathrm{O}_{16}$, с т.пл. $189-191{ }^{\circ} \mathrm{C}, \mathrm{R}_{f} 0,45$ (н-бутанол-уксусная кислота-вода 4 : 1 : 2). УФ-спектр $\left(\mathrm{C}_{2} \mathrm{H}_{5} \mathrm{OH}\right.$, $\lambda_{\max }$ нм): 256, 264 пл., 356 нм. ИК-спектр $\left(\mathrm{KBr}, v, \mathrm{~cm}^{-1}\right): 3595,3402(\mathrm{OH}), 1660(>\mathrm{C}=\mathrm{O}), 1605,1575,1510$ (ароматические двойные связи), 1085, 1062, 1025, 980, 900 (сахарный компонент), 815, 840 ( $n$-замещение в кольце «В»).

Флавонол 10 идентифицирован непосредственным подлинным образцом [22].<smiles>[R3]c1ccc(-c2oc3cc([R3])c([R4])c([R])c3c(=O)c2[R])cc1[R4]</smiles><smiles>[R1]c1cc([C@H]2Oc3cc(O)cc(O)c3CC2[R])cc(O)c1O</smiles>

$1: \mathrm{R}=\mathrm{R}_{1}=\mathrm{R}_{3}=\mathrm{R}_{5}=\mathrm{OH} ; \mathrm{R}_{2}=\mathrm{R}_{4}=\mathrm{H}$

5: $\mathrm{R}=\beta \mathrm{OH} ; \mathrm{R}_{1}=\mathrm{H}$

$2: \mathrm{R}=\mathrm{R}_{1}=\mathrm{R}_{3}=\mathrm{R}_{4}=\mathrm{R}_{5}=\mathrm{OH} ; \mathrm{R}_{2}=\mathrm{H}$

6: $\mathrm{R}=\alpha \mathrm{OGalloyl} ; \mathrm{R}_{1}=\mathrm{OH}$

3: $\mathrm{R}=\mathrm{R}_{1}=\mathrm{R}_{3}=\mathrm{R}_{5}=\mathrm{OH} ; \mathrm{R}_{2}=\mathrm{H} ; \mathrm{R}_{4}=\mathrm{OCH}_{3}$

$4: \mathrm{R}=\mathrm{R}_{2}=\mathrm{R}_{3}=\mathrm{R}_{4}=\mathrm{OCH}_{3} ; \mathrm{R}_{1}=\mathrm{R}_{5}=\mathrm{OH}$

7:R=-O- $\beta-D-$ Glc $p ; \mathrm{R}_{1}=\mathrm{R}_{3}=\mathrm{R}_{4}=\mathrm{R}_{5}=\mathrm{OH} ; \mathrm{R}_{2}=\mathrm{H}$

8: $\mathrm{R}=-O-\beta-D-\mathrm{Glc} p ; \mathrm{R}_{1}=\mathrm{R}_{3}=\mathrm{R}_{5}=\mathrm{OH} ; \mathrm{R}_{2}=\mathrm{H} ; \mathrm{R}_{4}=\mathrm{OCH}_{3}$

9:R=-O- $\alpha-L-\mathrm{Rha}-(1 \rightarrow 6)-\beta-D-\mathrm{Glc} ; \mathrm{R}_{1}=\mathrm{R}_{3}=\mathrm{R}_{5}=\mathrm{OH} ; \mathrm{R}_{2}=\mathrm{H} ; \mathrm{R}_{4}=\mathrm{OCH}_{3}$

10: $\mathrm{R}=-O-\alpha-L-\mathrm{Rha}-(1 \rightarrow 6)-\beta-D-\mathrm{Glc} ; \mathrm{R}_{1}=\mathrm{R}_{3}=\mathrm{R}_{4}=\mathrm{R}_{5}=\mathrm{OH} ; \mathrm{R}_{2}=\mathrm{H}$

\section{Выводы}

Изучен флавоноидный состав этилацетатный фракции водно-этанольного экстракта надземной части (стебли, листья, колючки и цветки) растения Alhagi canescens (Regel) B. Keller \& Shap., произрастающего в Узбекистане. В результате исследования впервые выделены и идентифицированы следующие флавоноиды: кемпферол (1), кверцетин (2), изорамнетин (3), хризоспленетин (4), (+)-катехин (5), (-)-эпигаллокатехингаллат (6), изокверцитрин (7), изорамнетин-3-O- $\beta-D$-глюкопиранозид (8), нарциссин (9) и рутин (10). Флавоноиды 1-3 и 7-10 отнесены к производным флавонола, соединения 4 - флавона, а соединения 5 и 6 - флаван-3-ола.

Выделенные флавоноиды обладают высокой биологической активностью, входят в состав комбинированных лекарственных препаратов, которые успешно применяются в медицине [25]. Следовательно, Alhagi canescens (Regel) B. Keller \& Shap. может служит источником их получения, а полученная вышеописанным способом этилацетатная фракция может быть рекомендована для дальнейшего изучения ее биологических свойств. 


\section{Список литературы}

1. Флора СССР. М., 1948. Т. 13. С. 367-373.

2. The Plant List [Electronic resourse]. URL: http://www.theplantlist.org

3. International Legume Database \& Information Service [Electronic resourse]. URL: http://www.ildis.org

4. Мавланов X. О генезисе и формировании видов Alhagi L. // Сборник трудов международной научнопрактической конференции. Ташкент, 2014. С. 32-33.

5. Определитель растений Средней Азии. Критерический конспект флоры. УзССР. 1981. Т. 6. С. 321-323.

6. Растительные ресурсы СССР. Цветковые растения, их химический состав, использование. Семейства Hydrangeaceae-Haloragaceae. Л., 1987. Т. 3. С. 103-105.

7. Muhammad G., Muhammad A.H., Farooq A., Muhammad A., Gilani A.H. Alhagi: A Plant Genus Rich in Bioactives for Pharmaceuticals // Phytother. Res. 2015. Vol. 29. Pp. 1-13.

8. Патент № 2402345 (РФ). Экстракт из растения Alhagi pseudalhagi, фармацевтическая и косметическая композиция на его основе, способы снижения содержания холестерина итриглицеридов в крови, снижения уровня продуктов окисления липидов, улучшения микроциркуляции, антиоксидантных свойств, улучшения состояния кожных покровов, стимулирования образования коллагена, ранозаживления и снижения воспаления / Э.Р. Абдурахманов, В.Н. Сыров / 27.10.2010.

9. Malik A., Kuliev Z.A., Akhmedov U.A., Vdovin A.D., Abdullaev N.D. Catechins and proanthocyanidins of Alhagi sparsifolia I. // Chemistry of Natural Compounds. 1997. Vol. 33. Pp. 174-178.

10. Alimova D.F., Kuliev Z.A., Vdovin A.D. Catechins and proanthocyanidines from Alhagi pseudoalhagi // Chemistry of Natural Compounds. 2010. Vol. 43. Pp. 326-327.

11. Alimova D.F., Nishanbaev S.Z., Kuliev Z.A., Vdovin A.D., Abdullaev N.D., Aripova S.F. New oligomeric proanthocyanidins from Alhagi pseudalhagi // Chemistry of Natural Compounds. 2010. Vol. 46. Pp. 357-362.

12. Mamatkulova N.M., Alimova D.F., Nishanbaev S.Z., Mukarramov N.I., Khidyrova N.K. Neutral substances from Alhagi pseudalhagi // Chemistry of Natural Compounds. 2012. Vol. 48. Pp. 908-909.

13. Alimova D.F., Eshbakova K.A., Bobakulov Kh.M., Abdullaev N.D. A new flavonol glycoside from the aerial part of Alhagi pseudalhagi // Chemistry of Natural Compounds. 2013. Vol. 49. Pp. 437-439.

14. Nishanbaev S.Z., Bobakulov Kh.M., Nigmatullaev A.M., Shamyanov I.D., Ohundedaev B.S., Abdullayev N.D. Volatile Compounds from the Aerial Parts of Four Alhagi Species Growing in Uzbekistan // Chemistry of Natural Compounds. 2016. Vol. 52. Pp. 167-170.

15. Ghosal S., Srivastava R.S. Chemical Investigation of Alhagi pseudalhagi (Bieb.) Desv.: $\beta$-Phenethylamine and Tetrahydroisoquinoline Alkaloids // Journal of Pharmaceutical Sciences. 1973. Vol. 62. N9. Pp. 1555-1556.

16. Zou G.A., Mansur S., Hu S.C., Aisa H.A., Shakhidoyatov Kh.M. Pyrrole alkaloids from Alhagi sparsifolia // Chemistry of Natural Compounds. 2012. Vol. 48 (4). Pp. 635-637.

17. Флора Узбекистана. Ташкент, 1955. Т. 3. С. 744-749.

18. Siddikov D.R., Nishanbaev S.Z., Narbutaeva D.A., Bobakulov Kh.M. Secondary metabolites from the aerial part of Geranium saxatile // Chemistry of Natural Compounds. 2013. Vol. 49. Pp. 343-344.

19. Сальникова Е.Н., Калинкина Г.И., Дмитрук С.Е. Химическое исследование флавоноидов полыни горькой (Artemisia absinthium L.), П. сиверса (A. sieversiana Willd.) и П. якутской (A. jacutica Drob.) // Химия растительного сырья. 2001. №3. С. 71-78.

20. Foo L.Y., Newman R., Waghorn G., Mcnabb W.C., Ulyat M.J. Proanthocyanidins from Lotus corniculatus // Phytochemistry. 1996. Vol. 41. Pp. 617-624.

21. Melikuziev F.A., Nishanbaev S.Z., Turgunov K.K., Bobakulov Kh.M. Phenolic compounds from roots of Rhodiola litvinovii // Chemistry of Natural Compounds. 2013. Vol. 49. Pp. 349-350.

22. Шилова И.В., Семенов А.А., Суслов Н.И., Короткова Е.И., Вторушина А.Н., Белякова В.В. Химический состав и биологическая активность фракции экстракта лабазника вязолистного // Химико-фармацевтический журнал. 2009. Т. 43. №4. С. 7-11.

23. Гужва Н.Н. Биологически активные вещества астрагала эспарцетного, произрастающего в Предкавказье // Химия растительного сырья. 2009. №3. С. 123-132.

24. Шарова О.В., Куркин В.А. Флавоноиды цветков календулы лекарственной // Химия растительного сырья. 2007. №1. C. 65-68.

25. Корулькин Д.Ю., Абилов Ж.А., Музычкина Р.А., Толстиков Г.А. Природные флавоноиды. Новосибирск, 2007. 229 c.

Поступило в редакциюю 29 июня 2016 г.

После переработки 2 ноября 2016 г. 
Nishanbaev S.Z. ${ }^{l}$, Bobakulov Kh.M. ${ }^{l}$, Beshko N.Y. ${ }^{2}$, Shamyanov I.D. ${ }^{l}$, Abdullaev N.D. ${ }^{l}$ FLAVONOIDS FROM THE AERIAL PARTS OF ALHAGI CANESCENS OF THE FLORA OF UZBEKISTAN

${ }^{I}$ Acad. S.Yu. Yunusov Institute of the Chemistry of Plant Substances Uzbek Academy of Sciences, ul. Mirzo Ulugbeka,

77, Tashkent, 100170 (Uzbekistan), e-mail: sabir78@rambler.ru

${ }^{2}$ Institute of the Gene Pool of Plants and Animals, Uzbek Academy of Sciences, ul. Bogishamol, 232, Tashkent, 100125 (Uzbekistan)

The aim of this work is the phytochemical research had not previously studied camel's-thorn species - Alhagi canescens - (greyish camel's-thorn). The species is distributed in the territory of Uzbekistan, Tajikistan, Turkmenistan, Afghanistan and in southern Kazakhstan, in Kyzylkum, Karakum desert, the valleys of the rivers Syrdarya and Amudarya, Syrdarya Karatau, South-Western Tien Shan and South Pamir-Alai.

Phenolic compounds from the aerial part (stems, leaves, thorns and flowers) of Alhagi canescens (Regel) B. Keller \& Shap. - (camel's-thorn, family Fabaceae) growing in Uzbekistan were studied. For the first time from this type of camel's-thorn by column chromatography of the ethyl acetate fraction of water-ethanol extract sequentially isolated following active flavonoids: kaempferol $(0,054 \mathrm{~g}, 0,22 \%$ in terms of the dry weight of the ethyl acetate extraction), quercetin $(0,065 \mathrm{~g}, 0,26 \%)$ isorhamnetin $(0,072 \mathrm{~g}, 0,29 \%)$, chrysosplenetin $(0,082 \mathrm{~g}, 0,33 \%),(+)$-catechin $(0,022 \mathrm{~g} ; 0,09 \%)$, (-)-epigallocatechingallate $(0,026 \mathrm{~g}, 0,10 \%)$ isoquercitrin $(0,087 \mathrm{~g}, 0,35 \%)$, isorhamnetin-3-O- $\beta$-D-glucopyranoside $(0,175 \mathrm{~g}, 0,7 \%)$, narcissin $(0,212 \mathrm{~g}$, $0,85 \%)$ and rutin $(0,108 \mathrm{~g}, 0,43 \%)$. The isolated flavonoids identified by spectral methods (IR-, UV- and NMR spectra) and by comparison with known authentically samples.

Keywords: Alhagi canescens (Regel) B. Keller \& Shap., Fabaceae, flavonols, flavones and flavan-3-ols.

\section{References}

1. Flora SSSR. [Flora of the USSR]. Moscow, 1948, vol. 13, pp. 367-373. (in Russ.).

2. The Plant List [Electronic resource]. URL: http://www.theplantlist.org

3. International Legume Database \& Information Service [Electronic resource]. URL: http://www.ildis.org

4. Mavlanov Kh. Sbornik trudov mezhdunarodnoi nauchno-prakticheskoi konferentsii. [Proceedings of the international scientific-practical conference]. Tashkent, 2014, pp. 32-33. (in Russ.).

5. Opredelitel' rastenii Srednei Azii. Kritericheskii konspekt flory. UzSSR. [Of plants of Middle Asia. Kriterichesky abstract flora. UzSSR]. Tashkent, 1981, vol. 6, pp. 321-323. (in Russ.).

6. Rastitel'nye resursy SSSR. Tsvetkovye rasteniia, ikh khimicheskii sostav, ispol'zovanie. Semeistva HydrangeaceaeHaloragaceae. [Plant resources of the USSR. Flowering plants, their chemical composition, the use. Families Hydrangeaceae-Haloragaceae]. Leningrad, 1987, vol. 3, pp. 103-105. (in Russ.).

7. Muhammad G., Muhammad A.H., Farooq A., Muhammad A., Gilani A.H. Phytother. Res., 2015, vol. 29, pp. 1-13.

8. Patent 2402345 (RU). 27.10.2010. (in Russ.).

9. Malik A., Kuliev Z.A., Akhmedov U.A., Vdovin A.D., Abdullaev N.D. Chemistry of Natural Compounds, 1997, vol. 33, pp. 174-178.

10. Alimova D.F., Kuliev Z.A., Vdovin A.D. Chemistry of Natural Compounds, 2010, vol. 43, pp. 326-327.

11. Alimova D.F., Nishanbaev S.Z., Kuliev Z.A., Vdovin A.D., Abdullaev N.D., Aripova S.F. Chemistry of Natural Compounds. 2010. vol. 46. pp. 357-362.

12. Mamatkulova N.M., Alimova D.F., Nishanbaev S.Z., Mukarramov N.I., Khidyrova N.K. Chemistry of Natural Compounds, 2012, vol. 48, pp. 908-909.

13. Alimova D.F., Eshbakova K.A., Bobakulov Kh.M., Abdullaev N.D. Chemistry of Natural Compounds, 2013, vol. 49, pp. 437-439.

14. Nishanbaev S.Z., Bobakulov Kh.M., Nigmatullaev A.M., Shamyanov I.D., Ohundedaev B.S., Abdullayev N.D. Chemistry of Natural Compounds, 2016, vol. 52, pp. 167-170.

15. Ghosal S., Srivastava R.S. Journal of Pharmaceutical Sciences, 1973, vol. 62, no. 9, pp. 1555-1556.

16. Zou G.A., Mansur S., Hu S.C., Aisa H.A., Shakhidoyatov Kh.M. Chemistry of Natural Compounds, 2012, vol. 48 (4), pp. 635-637.

17. Flora Uzbekistana. [Flora of Uzbekistan]. Tashkent, 1955, vol. 3, pp. 744-749. (in Russ.).

18. Siddikov D.R., Nishanbaev S.Z., Narbutaeva D.A., Bobakulov Kh.M. Chemistry of Natural Compounds, 2013, vol. 49, pp. 343-344.

19. Sal'nikova E.N., Kalinkina G.I., Dmitruk S.E. Khimiia rastitel'nogo syr'ia, 2001, no. 3, pp. 71-78. (in Russ.).

20. Foo L.Y., Newman R., Waghorn G., Mcnabb W.C., Ulyat M.J. Phytochemistry, 1996, vol. 41, pp. 617-624.

21. Melikuziev F.A., Nishanbaev S.Z., Turgunov K.K., Bobakulov Kh.M. Chemistry of Natural Compounds, 2013, vol. 49, pp. 349-350.

22. Shilova I.V., Semenov A.A., Suslov N.I., Korotkova E.I., Vtorushina A.N., Beliakova V.V. Khimikofarmatsevticheskii zhurnal, 2009, vol. 43, no. 4, pp. 7-11. (in Russ.).

23. Guzhva N.N. Khimiia rastitel'nogo syr'ia, 2009, no. 3, pp. 123-132. (in Russ.).

24. Sharova O.V., Kurkin V.A. Khimiia rastitel'nogo syr'ia, 2007, no. 1, pp. 65-68. (in Russ.).

25. Korul'kin D.Iu., Abilov Zh.A., Muzychkina R.A., Tolstikov G.A. Prirodnye flavonoidy. [Natural flavonoids]. Novosibirsk, 2007, 229 p. (in Russ.).

\footnotetext{
* Corresponding author.
} 
